This is a provisional PDF only. Copyedited and fully formatted version will be made available soon.

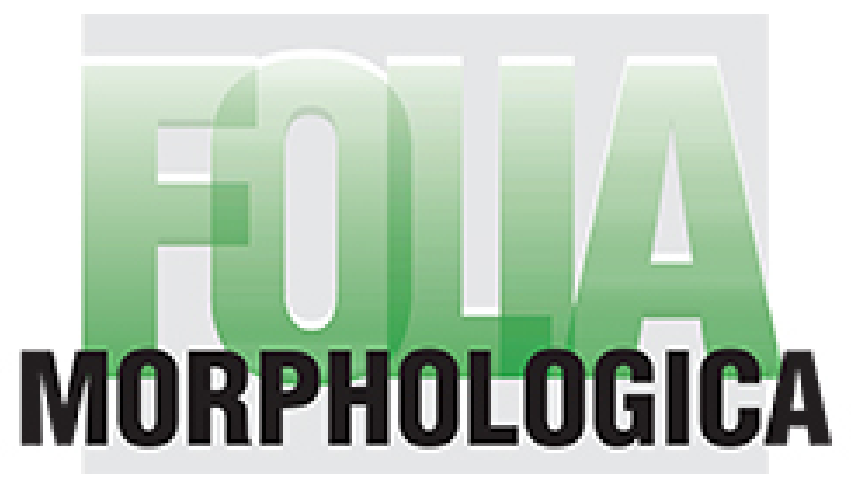

ISSN: 0015-5659

\title{
Comparison of color difference formulas to best distinguish resected areas of malignant brain tumors from their background using 5-aminolevulinic acid fluorescence
}

Authors: T. Szmuda, S. Ali, P. Słoniewski

DOI: $10.5603 / F M . a 2020.0035$

Article type: ORIGINAL ARTICLES

Submitted: $2020-02-03$

Accepted: $2020-02-26$

Published online: 2020-03-18

This article has been peer reviewed and published immediately upon acceptance.

It is an open access article, which means that it can be downloaded, printed, and distributed freely, provided the work is properly cited.

Articles in "Folia Morphologica" are listed in PubMed. 


\title{
Comparison of color difference formulas to best distinguish resected areas of malignant brain tumors from their background using 5-aminolevulinic acid fluorescence
}

Running head: Fluorescence color differences in brain tumors

\author{
T. Szmuda ${ }^{1 *}, \mathrm{~S} . \mathrm{Ali}^{2 *}$, P. Słoniewski ${ }^{1}$ \\ ${ }^{1}$ Neurosurgery Department, Medical University of Gdansk, Gdansk, Poland \\ ${ }^{2}$ Student's Scientific Circle, Neurosurgery Department, Medical University of Gdansk, \\ Gdansk, Poland \\ *Contributed equally to the manuscript
}

Address for correspondence: Tomasz Szmuda, Neurosurgery Department, Medical University of Gdansk, Poland. Address: Dębinki 7, Gdansk, Poland, 80-952. Email: tszmuda@gumed.edu.pl Tel.: 0048511280369 Fax: 0048583493330

\begin{abstract}
Background: Fluorescence-guided surgery (FGS) with 5-aminolevulinic acid (5-ALA) his proven to assist neurosurgeons to achieve a more complete brain tumour resection. However, 5-ALA-guided surgery is limited since it is often difficult to distinguish the colour difference between the resected areas of malignant brain tumours from their background. Our aim was to evaluate which colour difference formula was the most optimal to distinguish between malignant brain tumors from the background healthy tissue using 5-ALA fluorescence.
\end{abstract} Materials and methods: 37 patients with a primary or secondary malignant brain tumour ingested 5-ALA before the surgery. A $400 \mathrm{~nm}$ light was used to excite the fluorescence. Surgical videos were recorded for all the patients and a total of 183 samples were obtained from the fluorescent areas and their respective backgrounds. Three colour differences formulas - contrast ratio (CR), CIELab $\left(\Delta \mathrm{E}^{*}\right)$ and CIEDE2000 - were applied to the videos and compared using hot-cold maps. Baseline demographics, the tumour's location, the tumour's side, and tumour's World Health Organisation (WHO) grade was also analysed for correlations relating to the fluorescence. Chi-square and the Student's t-test were used for univariate relations. The three channels of the CIELAB colour space ( $\mathrm{L}^{*}, \mathrm{a}^{*}$ and $\left.\mathrm{b}^{*}\right)$ were analysed together and separately (since $\mathrm{L}^{*}$ of fluorescent areas was significantly higher than the background). 
Results: $\Delta \mathrm{E}^{*}$ resulted in good discrimination of $\mathrm{a}^{*}$ and $\mathrm{b}^{*}$, and moderate but acceptable discrimination of $\mathrm{L}^{*}$. CIEDE2000 distinguished differences in $\mathrm{a}^{*}$ and $\mathrm{b}^{*}$, although, not in $\mathrm{L}^{*}$. The CR distinguished only $\mathrm{L}^{*}$, whereas the probability of discriminating $\mathrm{a}^{*}$ and $\mathrm{b}^{*}$ channels failed. Neither age, sex, tumour location, tumour size or the WHO grade influenced the $a^{*}, b^{*}$ and $\mathrm{L}^{*}$ colour values $(\mathrm{p}>0.05)$. Colour differences measured by $\Delta \mathrm{E}^{*}$ and CIEDE2000 correlated together $(r=0.99, p<0.01)$, whereas $C R$ correlated only with $\Delta E(r=0.21, p=0.01)$ but not with CIEDE2000 ( $\mathrm{r}=0.07, \mathrm{p}=0.32)$.

Conclusions: $\Delta \mathrm{E}^{*}$ obtained the best colour discrimination between the resected areas of malignant brain tumours and the background when compared to CR and CIEDE2000. Therefore, $\Delta \mathrm{E}^{*}$ may be the best formula to help neurosurgeons distinguish the colour differences when operating malignant brain tumours with 5-ALA fluorescence.

Key words: 5-aminolevulinic acid, glioma surgery, colour perception, CIEDE2000, fluorescence

\section{INTRODUCTION}

Maximal tumour resection with minimal injury to the surrounding tissue remains the goal for neurological surgeons operating on malignant brain tumours [1-4]. Fluorescence-guided surgery (FGS), may assist in this matter as it allows better visualization of a patient's brain tumours, despite brain shift caused by a prolonged surgery or neuronavigational limitations [5]. This allows the physician to perform a more optimal resection for not only for malignant gliomas but also for recurrent glioblastomas [5,6]. 5-aminolevulinic acid (5-ALA) is commonly used for FGS as it is a natural haemoglobin metabolite, can be easily administered orally and carries minimal side effects [7].

After ingestion, it accumulates within malignant brain tissues and fluoresces in a violet-red colour after excitation with blue light.

Unfortunately, despite the promise of 5-ALA-guided resection, it remains greatly limited since 5-ALA fluorescence is sometimes difficult be distinguished from the background healthy tissue. This is crucial since, in practice, the decision to resect a section of a tumor is determined largely by the background colour [2]. To the human eye, slightly different colors may not be able to be distinguished. Thus, to objectively measure color, the CIELAB color system is used to reliably express color in three quantitive values denoted: $L^{*}, a^{*}$ and $b^{*}$. 
Several colour difference formulas have been proposed including: contrast ratio (CR), $\mathrm{CIELab}\left(\Delta \mathrm{E}^{*}\right)$ and CIEDE2000.

$\Delta \mathrm{E}^{*}$ was the very first formula proposed by the International Commission on Illumination (CIE) to measure distance between colours. However, over time, they updated their colour difference formula to CIEDE2000 to account for non-uniformities in human colour vision. CIEDE2000 has also been established as the International Organization for Standardization (ISO) standard. However, these general recommendations may not be the most optimal to distinguish brain tumors due to the highly specific physical qualities of brain tissue and brain tumors. Studies have shown that color perception is highly unique depending on the part of the human body and tissue studied [8,9]. To our knowledge, no study has yet been done to determine of the best color difference formula(s) regarding brain tumors.

We sought to evaluate which colour difference parameter was the most optimal to distinguish between malignant brain tumors and the background using 5-ALA fluorescence. To accomplish this, we utilized numerous color difference formulas (i.e. $\mathrm{CR}, \Delta \mathrm{E}^{*}$ or CIEDE2000) on the neurosurgical recordings of patients with brain tumors.

\section{MATERIALS AND METHODS}

\section{Patients}

37 patients with a brain tumour were prospectively collected (22 males and 15 females; age 23-81 years, mean \pm SD: $58.2 \pm 16.3$, and median age: 64 ). These patients were treated at the Neurosurgery Department at the Medical University of Gdańsk in Gdańsk, Poland, from August 2015 to December 2019. We collected baseline demographic data (age and sex), tumour location (within the lobe and the hemisphere), histopathology, and the World Health Organisation (WHO) tumour grade. The protocol of the study was approved by the local bioethical committee (permission number NKBBN/98/2012). The study is a continuation of our previous observations and includes a similar methodology for colour analysis [2].

\section{Surgery}

Four hours prior to anaesthesia, 5-ALA (Gliolan, Medac GmbH; Wedel, Germany) was given orally to each patient. Following craniotomy, MRI-based navigation helped to remove the gross parts of the tumour under white light. Diffusion tensor tractography highlighted white matter tracts (cerebrospinal tract or arcuate fasciculus) and limited resection of the tumours located near the eloquent areas. 
Afterwards, a blue light was used to identify the remaining tumour and a white light was turned on for further resection. The surgery was carried out in this way until the operating neurosurgeon deemed the tumour to be completely resected. In all the surgeries, the duration from 5-ALA intake to the end of surgical resection was about 9 hours.

\section{Equipment}

Preoperative Magnetic resonance imaging was performed on all patents (1.5 Tesla, according to the site-specific protocol, including contrast enhanced (CE) T1, T2-weighted, spectroscopy and diffusion weighed scenes). The StealthViz application (Medtronic Inc., Minneapolis) and StealthStation S7 navigation (Medtronic Navigation; Louisville, CO, USA) assisted all the surgeries. Blue-light filtering of the surgical microscope (OPMI Pentero with fluorescence kit BLU 400, Carl Zeiss, Germany) met the European Medical Device Directive 93/42/EEC requirements. The microscope included an integrated digital camera MKC-500HD (Ikegami Co.; Tokyo, Japan). Camera specifications were as follows: high-definition matrix 1920x1080p, 54dB signal-to-noise ratio, sensitivity of F12 at $2000 \mathrm{lux} / 3200^{\circ} \mathrm{K}$ and a $1 / 3$-inch CMOS image sensor. Light sensitivity and white balance remained constant at the default settings. Spectral sensitivity and light filtering in the microscope and camera were unattainable from the manufacturers. The excitation wavelength range was 400-410nm and the observation wavelength range was 620-710nm. Room luminance remained constant during the entire surgery and study.

Surgical recordings were examined on a Dell U2410 32' monitor (1920x1200p, 16:10 widescreen aspect ratio, 80000:1 dynamic contrast ratio, colour depth of 1.07 billion and 100\% coverage of CIE L*a*b* colour gamut 7). Shotcut software v.5.2.0 (Digia Inc.; Santa Clara, CA, USA) was used for video playback without any video filtering.

\section{Study design and colour analysis}

The neurosurgical recordings were watched and points of interest to be included into this study's colorimetric evaluation were chosen if: (1) an area demonstrated fluorescence by the naked eye regardless of its future surgical removal and (2) if an area was delineated by the adjacent background by a different colour.

The points of interests were chosen from the video. Then, Colour Contrast Analyser v.2.5 (WAT Consortium, int'l) was used to probe the area with RGB colour model values. Both the fluorescent region and the corresponding background of the tumour was analysed in this way. 
Afterwards, the RGB model was transformed into the CIELAB colour space which consisted of three colour coordinates denoted $\mathrm{L}^{*}, \mathrm{a}^{*}$ and $\mathrm{b}^{*}$ ( $\mathrm{L}^{*}$ denotes lightness, $\mathrm{a}^{*}$ describes a red or green value and $b^{*}$ describes a yellow or blue value).

Using these values, the following formulas found colour differences from the same pool of samples: $\Delta \mathrm{E}^{*}, \mathrm{CIEDE} 2000$ and Contrast Ratio (CR). $\Delta \mathrm{E}^{*}$ measures the difference between two colours $\left(\mathrm{L}^{*}, \mathrm{a}^{*}\right.$ and $\left.\mathrm{b}^{*}\right)$. CR compares relative luminance (i.e. all colours are converted to greyscale) and it is the key parameter distinguishing colours. CIEDE2000 is a complex formula taking into account several metrics to compensate for neutral colours, lightness, chroma and hue.

CIEDE2000, $\triangle \mathrm{E}$ and $\mathrm{CR}$ calculated colour differences and their formulas are presented below:

CIEDE2000 (CIE Publ. 142-2001, CIE S 014-6/E:2013)

$$
\begin{aligned}
& \Delta \mathrm{E}^{*}=\sqrt{ }\left((\mathrm{L} 1-\mathrm{L} 2)^{\wedge} 2+(\mathrm{a} 1-\mathrm{a} 2)^{\wedge} 2+(\mathrm{b} 1-\mathrm{b} 2)^{\wedge} 2\right) \\
& \mathrm{CR}=(\mathrm{L} 1+0.05) /(\mathrm{L} 2+0.05)
\end{aligned}
$$

where L1 and L2 represent relative lighter and darker colour luminance respectively; a1, b1 and a1, b1 signify dimensions of lighter and darker colours respectively.

$\Delta E^{*}$, CIEDE2000 and RGB to CIE $1976 \mathrm{~L}^{*} \mathrm{a}^{*} \mathrm{~b} *$ transformations were calculated using an electronic spread sheet (Microsoft Office Excel 2010 for Windows). CR was calculated using Colour Contrast Analyser software.

\section{Statistical analysis}

Statistica Software v.10.0 (StatSoft Inc.; Tulsa, OK, USA), was used for performing Chisquare, Student's t-test and their non-parametric equivalents. Continuous variables are expressed as mean \pm standard deviation (SD). A P value of $<0.05$ was considered statistically significant. Figure 1 illustrates the methodology of probing fluorescent areas and their surroundings. Figure 2 was created using Prism v.6.07 (GraphPad; La Jolla, CA, USA). Hotcold maps in Figure 3 were created using Past (Hammer and Harper, Øyvind Hammer, Natural History Museum, University of Oslo).

\section{Study objective}


Our aim was to evaluate various colour difference formulas (CR, $\Delta \mathrm{E}^{*}$ and CIEDE2000) that distinguish fluorescent areas from the background. We attempted this by analysing the area of CIELAB colour space under $400 \mathrm{~nm}$ illumination and probed fluorescent points and their background.

\section{RESULTS}

The clinical course and outcome were not the scope of the study. 27 patients (73.0\%) had glioblastoma and 2 (5.4\%) had gliosarcoma. Out of the primary brain tumours, all were malignant except for one patient with gemistic astrocytoma (WHO 2 grade). Out of the total 37 patients, there were $14(37.8 \%)$ surgeries of recurrent or progressive tumours. The most common locations of the tumour were at the temporal lobe $(n=16,43.2 \%)$ and the frontal lobe $(n=9,24.3 \%)$. We obtained 183 samples of fluorescent areas and 183 samples of their respective background. The detailed chart of sampled values is presented on Supplementary Table 1.

The results of all the CIELAB colour space channels are illustrated on Figure 2.

\section{Colour difference}

$\Delta \mathrm{E}$ and CIEDE2000 correlated together $(\mathrm{r}=0.99, \mathrm{p}<0.01)$. $\mathrm{CR}$ correlated only with $\Delta \mathrm{E}$ $(\mathrm{r}=0.21, \mathrm{p}=0.01)$ but not with CIEDE2000 ( $\mathrm{r}=0.07, \mathrm{p}=0.32)$. Age, sex, the number of samples, brain hemisphere, location of the tumour and glioblastoma histopathology did not influence the fluorescent areas or their background colour values $\left(\mathrm{a}^{*}, \mathrm{~b}^{*}\right.$ and $\left.\mathrm{L}^{*}\right)(\mathrm{P}$ always $>0.05)$. Descriptive statistics of all colour difference parameters are presented on Table 1 and Figure 3 illustrates those findings. $\Delta \mathrm{E}$ resulted in good discrimination of $\mathrm{a}^{*}$ and $\mathrm{b}^{*}$, and moderate but acceptable discrimination of $\mathrm{L}^{*}$. CR distinguished only $\mathrm{L}^{*}$, whereas the probability of discriminating $\mathrm{a}^{*}$ and $\mathrm{b}^{*}$ channels failed. CIEDE2000 distinguished differences in $\mathrm{a}^{*}$ and $\mathrm{b}^{*}$ axes, however, not in $\mathrm{L}^{*}$.

\section{DISCUSSION}

\section{Key findings:}


We found that $\Delta \mathrm{E}^{*}$ best distinguished colour differences between the resected areas of malignant brain tumours and the background with 5-ALA fluorescence compared to other established colour difference formulas, namely CIEDE2000 and CR. By utilizing this optimal colour difference formula for intracranial tumours, neurosurgeons can further appreciate and enjoy the benefits of 5-ALA FGS by performing more complete tumour resections. Our findings are clinically profound since a greater extent of tumour resection may lead to several favourable prognostic implications for the patient. Even in patients with glioblastoma- $\mathrm{a}$ tumour with an especially poor prognosis - a greater extent of resection is still a proven benefit to patients [10-12]. To our best knowledge, this study is the first to compare the colour difference formulas among intracranial tumours. Moreover, our findings challenge the current ISO colour difference standard (i.e. CIEDE2000, which is recommended by the CIE).

\section{Context}

Gómez-Polo $\mathrm{C}$ et al — on their colour experiments conducted on the human gingiva — found that CIEDE2000 imitated colour differences better than $\Delta \mathrm{E}^{*}$, however, in a later experiment found that both formulas reflected color differences in a similar fashion $[9,13]$. Our results disagree with Gómez-Polo $\mathrm{C}$ et al as we found that $\Delta \mathrm{E}^{*}$ best distinguished colour differences, however, we reiterate that our experiments were conducted on malignant intracranial tumours which may express 5-ALA fluorescence much different colours than the human gingiva. Therefore, we do not discredit CIEDE2000, but postulate that it may not be the most superior in distinguishing colour differences with malignant brain tumours.

In our previous study on 5-ALA, we proved that surgeons make a decision of tumour resection based on colour contrast (like CR), and not on colour fluorescence [2]. Therefore, in our study, we compared the CR with $\triangle \mathrm{E}^{*}$ and CIEDE2000. In this study, the CR formula distinguished colour difference the best in the $\mathrm{L}^{*}$ section of colour space (the shades from black to white) compared to $\triangle E^{*}$ and CIEDE2000. However, we realize that since CR is calculated solely on $\mathrm{L}^{*}$, it has a limited use when discriminating other colour parameters (e.g. pink fluorescence from a grey background).

A 2011 study on 5-ALA first explored the advantages of measuring 5-ALA-induced fluorescent-metabolites in vivo [14]. Therefore, our study adopted a similar method as the spectra of colours were measured intraoperatively. Their study also concluded that 5-ALA may be used for not only high-grade glioma, but other tumours as well. Our results, support these findings as 5-ALA was able to discriminate between normal and malignant tumour 
tissue in a variety of tumours (i.e. glioblastoma, anaplastic oligodendroglioma and anaplastic astrocytoma).

\section{Limitations}

We realize that there is an inherent challenge in measuring colour difference due to the heterogeneous perception of colour among every individual that is problematic to overcome. However, the formulas used in our study to distinguish colour differences are established and reproducible.

Moreover, it is possible that blood or other organic brain debris might have covered parts of the fluorescing tumour, making colour analysis complicated. Removing unwanted material and preserving a clear view of the operating field is the responsibility of the operating neurosurgeon. We confirm that the neurosurgeons operating on the tumours included in the study had more than 15 years of neurosurgical experience at a university hospital, and thus, assume that they maintained an adequate view of the surgical field at least for the purposes of this study.

\section{Future directions}

In our study, both fluorescence and background colour space sections partially overlapped (see Figure 2). Therefore, we recommend that future studies on 5-ALA fluorescence include a more specific section of colour space to further highlight fluorescence differences.

We recommend that confirmatory studies be done in other centres around the world to help determine if slight differences in colour perception among populations may be significant enough to warrant colour research specific to a particular population or sub-population [15]. Of note, the neurosurgeons that performed that surgeries were of Polish descent.

Our study was conducted on an adult population. Future studies may conduct a similar study on a paediatric population as current research suggests that 5-ALA assisted surgery may aid in the resection of paediatric brain tumours as well [16].

\section{Clinical implications}

Several studies have demonstrated that the human visual system may be augmented by fluorescence targeting with 5-ALA and lead to a more extensive tumour resection [17-20] Fortunately, the cost of FGS is relatively low when compared to intraoperative magnetic resonance imaging (which has proven to maximize tumour resection) giving FGS an economical and practical advantage [21]. FGS with 5-ALA is one of the most innovative 
treatments in contemporary neurological surgery as it offers the surgeon intraoperative visualization of the tumour to a much greater extent than traditional white-light microscopy. By studying which mathematical formula(s) may best distinguish healthy tissue from malignant tissue, neurosurgeons may be empowered to excise a greater extent of the residual tumour tissue while preserving healthy tissue. FGS with 5-ALA has proven to be more effective than conventional neuronavigation-guided neurosurgery in identifying tumour margins, enhancing the extent of malignant tumour resections, promising a longer progression-free survival and increasing the quality of life of patients [22-24].

\section{CONCLUSIONS}

In our study $\Delta \mathrm{E}^{*}$ best distinguished fluorescent areas from the background compared to CIEDE2000 and CR. Therefore, we recommend $\Delta E^{*}$ to be used by neurological surgeons operating on intracranial tumours as it discriminates colour differences most optimally.

\section{Acknowledgements}

We thank Mr. Aleksander Och for his assistance throughout our study.

\section{REFERENCES}

[1] Szmuda T, Rogowska M, Słoniewski P, Abuhaimed A, Szmuda M, Springer J, et al. Frontal aslant tract projections to the inferior frontal gyrus. Folia Morphol (Warsz) 2015. doi:10.5603/FM.a2017.0039.

[2] Szmuda T, Słoniewski P, Olijewski W, Springer J, Waszak PM. Colour contrasting between tissues predicts the resection in 5-aminolevulinic acid-guided surgery of malignant gliomas. J Neurooncol 2015. doi:10.1007/s11060-015-1750-0.

[3] Krakowiak M, Słoniewski P, Dzierżanowski J, Szmuda T. Future of the nerve fibres imaging: tractography application and development directions. Folia Morphol (Warsz) 2015;74:290-4. doi:10.5603/FM.2015.0044.

[4] Yu Q, Lin K, Liu Y, Li X. Clinical Uses of Diffusion Tensor Imaging Fiber Tracking Merged Neuronavigation with Lesions Adjacent to Corticospinal Tract : A 
Retrospective Cohort Study. J Korean Neurosurg Soc 2019. doi:10.3340/jkns.2019.0046.

[5] Hadjipanayis CG, Widhalm G, Stummer W. What is the surgical benefit of utilizing 5aminolevulinic acid for fluorescence-guided surgery of malignant gliomas? Neurosurgery 2015;77:663-73. doi:10.1227/NEU.0000000000000929.

[6] Lu VM, Jue TR, McDonald KL, Rovin RA. The Survival Effect of Repeat Surgery at Glioblastoma Recurrence and its Trend: A Systematic Review and Meta-Analysis. World Neurosurg 2018;115:453-459.e3. doi:10.1016/j.wneu.2018.04.016.

[7] Collaud S, Juzeniene A, Moan J, Lange N. On the selectivity of 5-aminolevulinic acidinduced protoporphyrin IX formation. Curr Med Chem - Anti-Cancer Agents 2004;4:301-16. doi:10.2174/1568011043352984.

[8] Ling F, Paul E, Furzer R. Colour difference of subcutaneous fat and palmar fat pad in open carpal tunnel release. ANZ J Surg 2014;84:856-60. doi:10.1111/ans.12754.

[9] Gómez-Polo C, Montero J, Gómez-Polo M, Martin Casado A. Comparison of the CIELab and CIEDE 2000 Color Difference Formulas on Gingival Color Space. J Prosthodont 2017. doi:10.1111/jopr.12717.

[10] Haj A, Doenitz C, Schebesch KM, Ehrensberger D, Hau P, Putnik K, et al. Extent of resection in newly diagnosed glioblastoma: Impact of a specialized neuro-oncology care center. Brain Sci 2018;8. doi:10.3390/brainsci8010005.

[11] Shonka NA, Aizenberg MR. Extent of Resection in Glioblastoma. J Oncol Pract 2017;13:641-2. doi:10.1200/jop.2017.027599.

[12] Stummer W, Reulen HJ, Meinel T, Pichlmeier U, Schumacher W, Tonn JC, et al. Extent of resection and survival in glioblastoma multiforme: Identification of and adjustment for bias. Neurosurgery 2008;62:564-74. doi:10.1227/01.neu.0000317304.31579.17.

[13] Gómez-Polo C, Muñoz MP, Lorenzo Luengo MC, Vicente P, Galindo P, Martín Casado AM. Comparison of the CIELab and CIEDE2000 color difference formulas. J Prosthet Dent 2016;115:65-70. doi:10.1016/j.prosdent.2015.07.001.

[14] Valdés PA, Leblond F, Kim A, Harris BT, Wilson BC, Fan X, et al. Quantitative 
fluorescence in intracranial tumor: implications for ALA-induced PpIX as an intraoperative biomarker. J Neurosurg 2011;115:11-7. doi:10.3171/2011.2.JNS101451.

[15] Webster MA, Webster SM, Bharadwaj S, Verma R, Jaikumar J, Madan G, et al. Variations in normal color vision III Unique hues in Indian and United States observers. J Opt Soc Am A 2002;19:1951. doi:10.1364/josaa.19.001951.

[16] Schwake M, Schipmann S, Müther M, Köchling M, Brentrup A, Stummer W. 5-ALA fluorescence-guided surgery in pediatric brain tumors - a systematic review. Acta Neurochir (Wien) 2019;161:1099-108. doi:10.1007/s00701-019-03898-1.

[17] Suero Molina E, Schipmann S, Stummer W. Maximizing safe resections: the roles of 5aminolevulinic acid and intraoperative MR imaging in glioma surgery-review of the literature. Neurosurg Rev 2019;42:197-208. doi:10.1007/s10143-017-0907-z.

[18] Widhalm G, Wolfsberger S, Minchev G, Woehrer A, Krssak M, Czech T, et al. 5Aminolevulinic acid is a promising marker for detection of anaplastic foci in diffusely infiltrating gliomas with nonsignificant contrast enhancement. Cancer 2010;116:154552. doi:10.1002/cncr.24903.

[19] Roberts DW, Valdés PA, Harris BT, Fontaine KM, Hartov A, Fan X, et al. Coregistered fluorescence-enhanced tumor resection of malignant glioma: Relationships between $\delta$-aminolevulinic acid-induced protoporphyrin IX fluorescence, magnetic resonance imaging enhancement, and neuropathological parameters: Clinical article. J Neurosurg 2011;114:595-603. doi:10.3171/2010.2.JNS091322.

[20] Floeth FW, Stummer W. The value of metabolic imaging in diagnosis and resection of cerebral gliomas. Nat Clin Pract Neurol 2005;1:62-3. doi:10.1038/ncpneuro0043.

[21] Eljamel MS, Mahboob SO. The effectiveness and cost-effectiveness of intraoperative imaging in high-grade glioma resection; a comparative review of intraoperative ALA, fluorescein, ultrasound and MRI. Photodiagnosis Photodyn Ther 2016;16:35-43. doi:10.1016/j.pdpdt.2016.07.012.

[22] Zhao S, Wu J, Wang C, Liu H, Dong X, Shi C, et al. Intraoperative FluorescenceGuided Resection of High-Grade Malignant Gliomas Using 5-Aminolevulinic AcidInduced Porphyrins: A Systematic Review and Meta-Analysis of Prospective Studies. PLoS One 2013;8. doi:10.1371/journal.pone.0063682. 
[23] Su X, Huang QF, Chen HL, Chen J. Fluorescence-guided resection of high-grade gliomas: A systematic review and meta-analysis. Photodiagnosis Photodyn Ther 2014;11:451-8. doi:10.1016/j.pdpdt.2014.08.001.

[24] Stummer W, Pichlmeier U, Meinel T, Wiestler OD, Zanella F, Reulen HJ.

Fluorescence-guided surgery with 5-aminolevulinic acid for resection of malignant glioma: a randomised controlled multicentre phase III trial. Lancet Oncol 2006;7:392401. doi:10.1016/S1470-2045(06)70665-9.

(Table 1)

\begin{tabular}{|c|c|c|c|c|c|c|c|c|c|}
\hline Value & Mean & $\begin{array}{l}\text { Medi } \\
\text { an }\end{array}$ & $\begin{array}{l}\text { Mini } \\
\text { mum }\end{array}$ & $\begin{array}{l}\text { Maxi } \\
\text { mum }\end{array}$ & $\begin{array}{l}\text { Lowe } \\
\mathrm{r} \\
\text { quarti } \\
\text { le }\end{array}$ & $\begin{array}{l}\text { Upper } \\
\text { quartile }\end{array}$ & $\begin{array}{l}\text { Stand } \\
\text { ard } \\
\text { deviat } \\
\text { ion }\end{array}$ & $\begin{array}{l}\text { Standard } \\
\text { error of } \\
\text { mean }\end{array}$ & \\
\hline foreground $\mathrm{L}^{*}$ & 65.80 & 66.67 & 30.40 & 93.97 & 59.81 & 72.86 & 11.81 & 0.873025 & \multirow{2}{*}{$<0.01$} \\
\hline background L* & 45.19 & 45.62 & 11.01 & 72.47 & 37.47 & 53.03 & 11.26 & 0.832113 & \\
\hline fluorescence $\mathrm{a}^{*}$ & 51.03 & 49.12 & $11.93^{-}$ & 97.30 & 38.06 & 64.56 & 20.87 & 1.542679 & \multirow{2}{*}{$<0.01$} \\
\hline background a* & -3.37 & -5.78 & $28.73^{-}$ & 49.91 & 13.87 & 4.3332 & 14.76 & 1.090750 & \\
\hline fluorescence $b^{*}$ & -22.55 & 24.69 & $61.88^{-}$ & 20.67 & 33.05 & -11.38 & 17.90 & 1.323546 & \multirow{2}{*}{$<0.01$} \\
\hline background $b^{*}$ & 9.84 & 13.53 & $58.39^{-}$ & 44.82 & 0.27 & 22.49 & 18.82 & 1.391401 & \\
\hline$\Delta \mathrm{E}$ & 42.51 & 41.55 & 14.10 & 78.66 & 30.58 & 55.17 & 14.82 & 1.096059 & \\
\hline $\begin{array}{l}\text { contrast ratio } \\
(\mathrm{CR})\end{array}$ & 2.11 & 1.90 & 1.00 & 4.80 & 1.70 & 2.50 & 0.65 & 0.047958 & \\
\hline CIEDE2000 & 66.10 & 65.19 & 15.15 & $\begin{array}{r}145.0 \\
7\end{array}$ & 47.41 & 83.21 & 25.49 & 1.884512 & \\
\hline
\end{tabular}

Table 1. Colour parameters and colour difference parameters between the fluorescent areas and the background. $\mathrm{L}^{*}, \mathrm{a}^{*}$ and $\mathrm{b}^{*}$ are CIELAB colour space values; colour difference was expressed by means of $\Delta \mathrm{E}$, contrast ratio (CR) and CIEDE2000.

Figure 1. This illustration shows how colour parameters were obtained and analysed from the surgery.

(A) The view of the neurosurgical operative area illuminated under normal white-light.

(B) The same view of the operative area, however, illuminated by a $400 \mathrm{~nm}$ blue light so that the fluorescence indicated the tumour (pink arrow on B).

(C) A picture was taken and was analysed on the computer; the fluorescence (pink arrow) and the background (grey arrow) were chosen and the were coded on the RGB colour space. The contrast ratio was calculated automatically by the software (red rectangle). 
Figure 2. Colours of fluorescing areas and the surrounding background in the three channels of the CIELAB colour space: $a^{*}$ (green (-) to red (+)), b* (blue (-) to yellow (+)) and L* for lightness from black to white. Since all three channels could not be represented feasibly on one three-dimensional graph (A) represents $a^{*}$ and $b^{*}$ while (B) represents only $L^{*}$ on the CIELAB colour space. Both (A) and (B) show a difference in the colour of the background (black crossed square) and the florescence (violet encircled dots), however, there is also overlap between the two in $\mathrm{L}^{*}, \mathrm{a}^{*}$ and $\mathrm{b}^{*}$.

(A) Most of the fluorescent areas were located in Quadrant III (the purple area) while the background colours were located mostly in Quadrant I (the green area).

(B) The lightness $\left({ }^{*} \mathrm{~L}\right)$ of most of the fluorescent areas was higher than its background. Abbreviations: CIELAB - colour space defined by the International Commission on Illumination.

Figure 3. Hot-cold probability maps show to what extent the contrast ratio (CR), CIEDE2000 and $\triangle \mathrm{E}$ distinguished colour differences in the three channels of the CIELAB colour space $\left(\mathrm{L}^{*}, \mathrm{a}^{*}\right.$ and $\left.\mathrm{b}^{*}\right)$. One may consider "solid or more distinct colour bands" to illustrate significant probabilities (e.g. $\Delta \mathrm{E}$ for $\mathrm{a}^{*}, \mathrm{~b}^{*}$ and $\mathrm{L}^{*}$ ) while "scattered colours" illustrate nonsignificant probabilities (CIEDE2000 for $\mathrm{L}^{*}$ and CR for $\mathrm{a}^{*}$ and $\mathrm{b}^{*}$ ). 


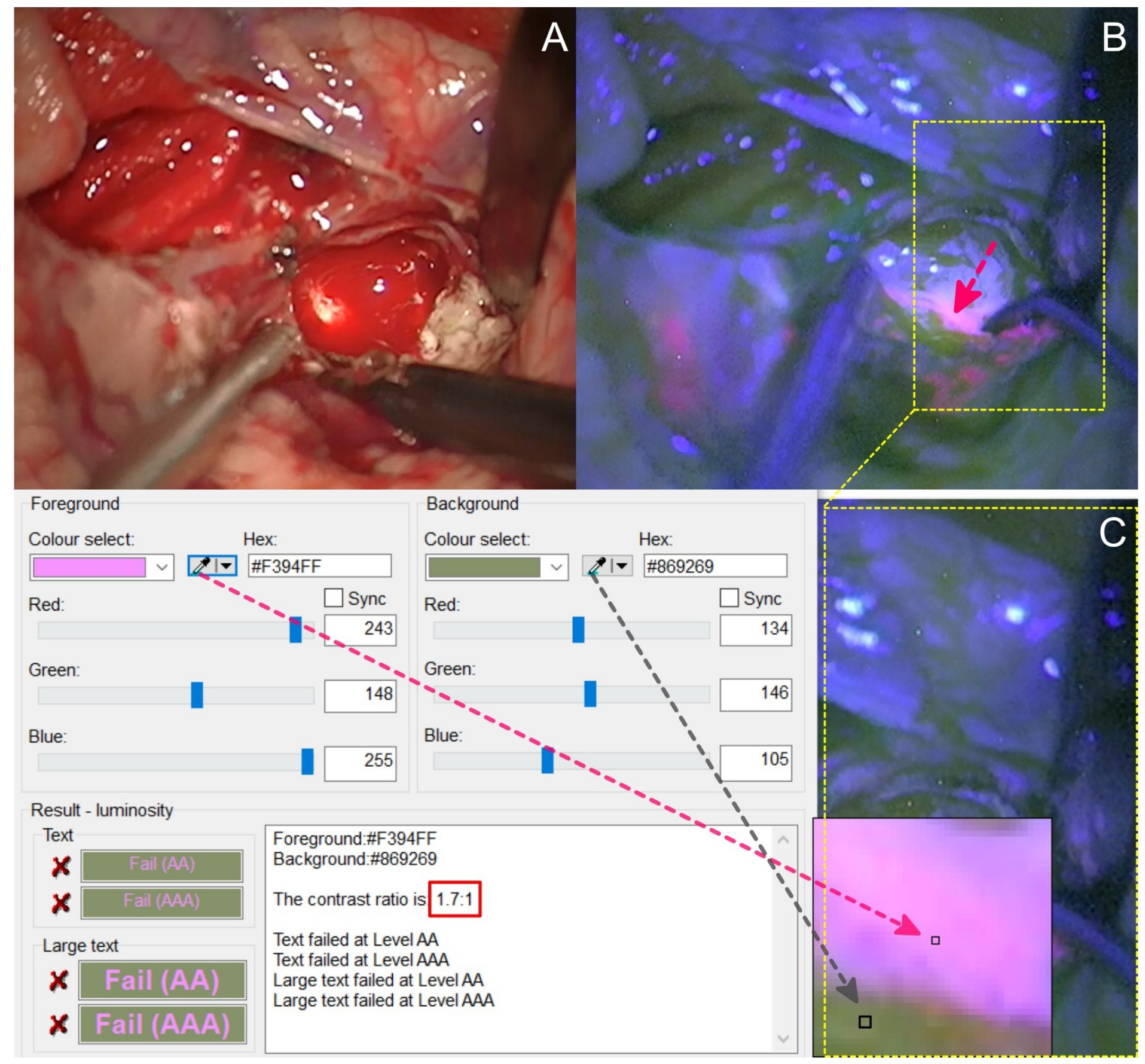



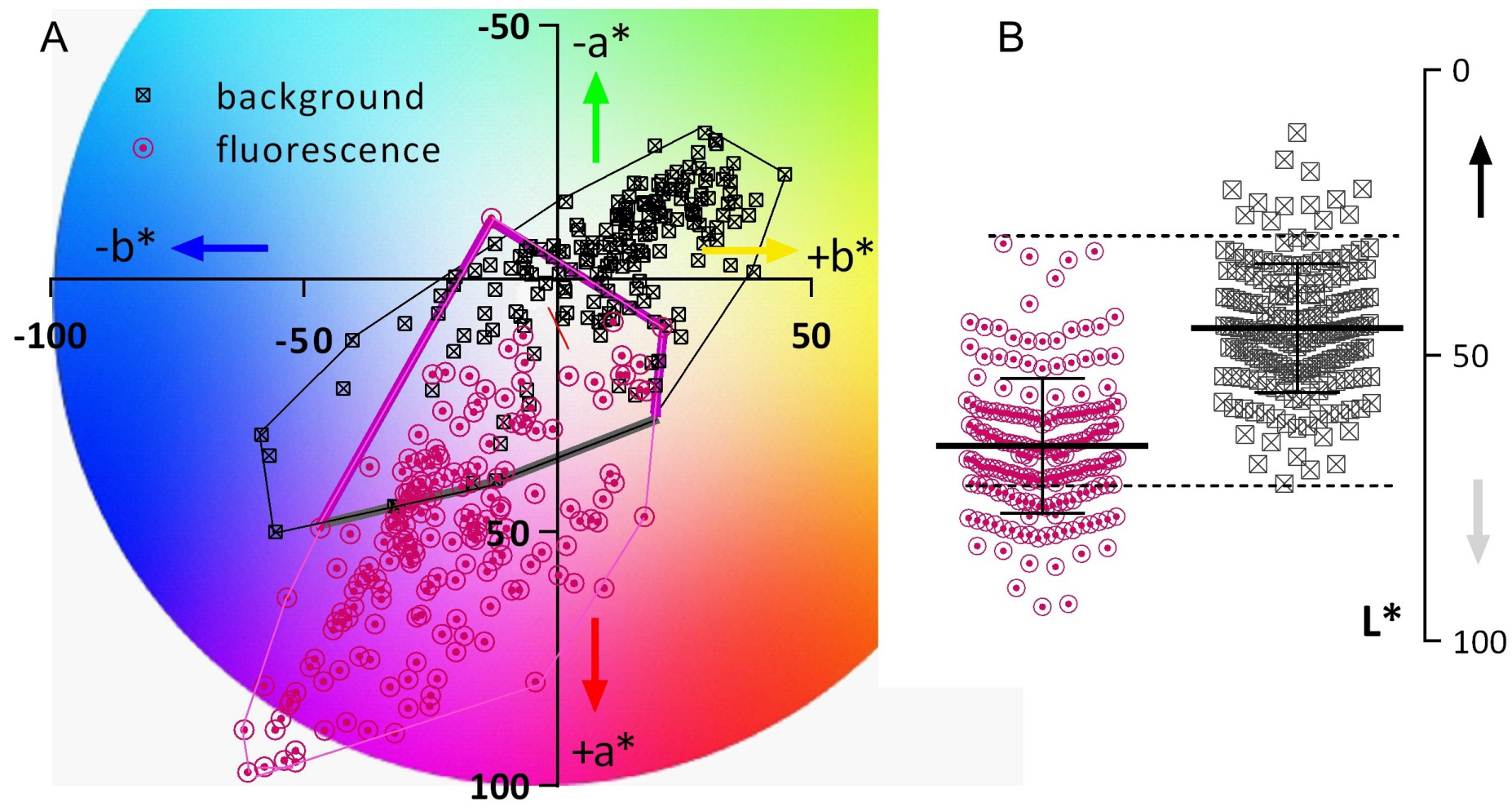


\section{Contrast Ratio (CR)}
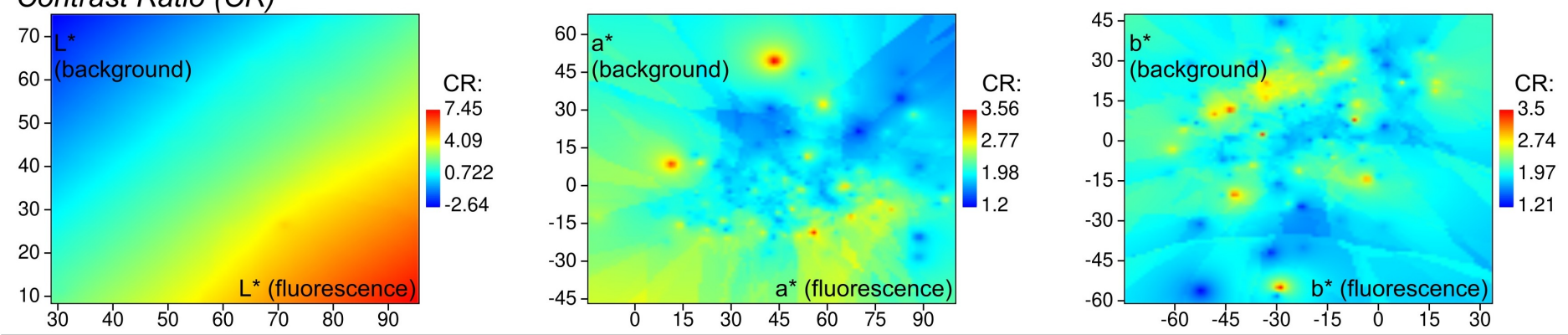

\section{CIEDE2000}
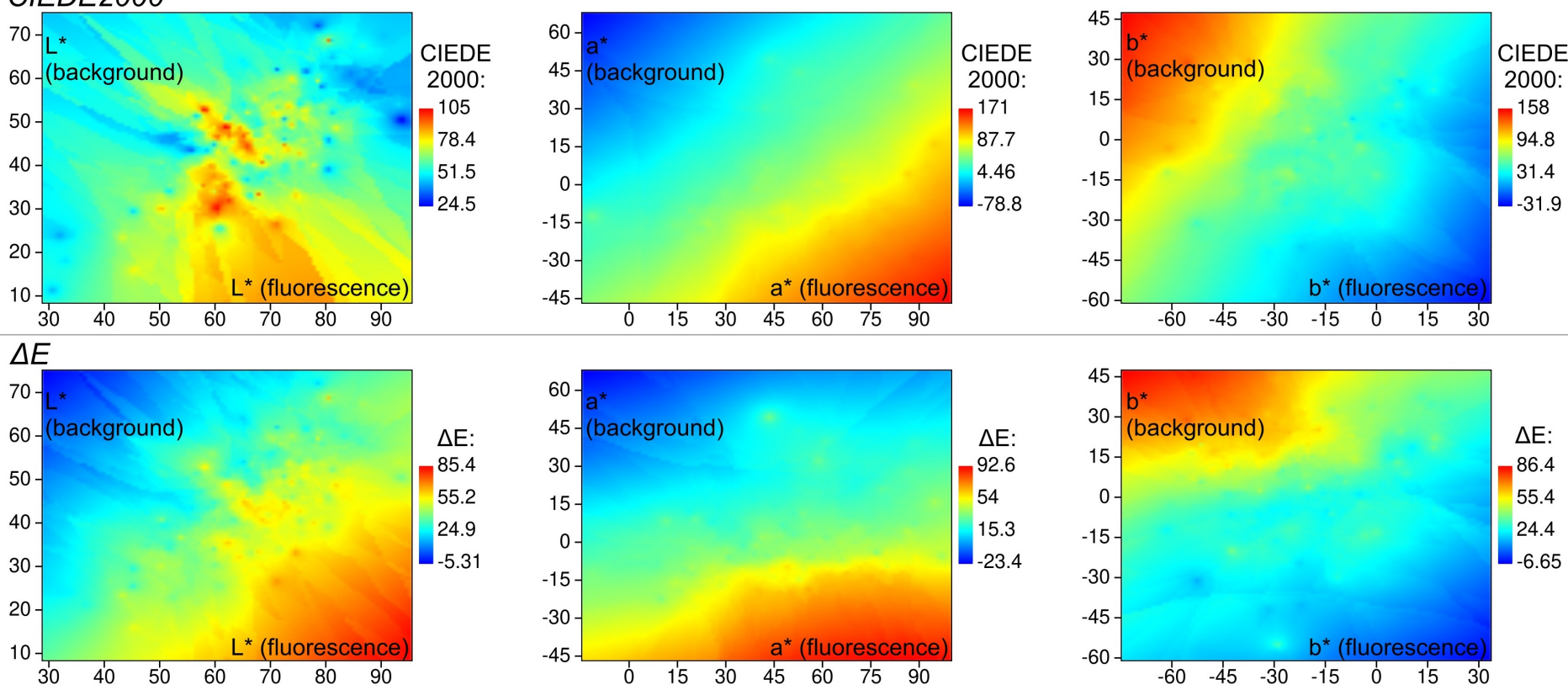